\title{
Stakeholders' network in Iranian health policy-making: A model for participatory policy-making
}

\author{
Behzad Damari ${ }^{1}$, Abass Vosoogh Moghadam ${ }^{2,3}$, Narges Rostamigooran ${ }^{2,3 *}$ \\ Received: 13 Jun 2016 Published: 19 Dec 2017
}

\begin{abstract}
Background: Stewardship, resource generation, financing, and providing services are the 4 main functions in any health system. Using intelligence and common sense in making policies and decisions is a subcomponent of the stewardship. The present study aimed at designing a model that provides better access to the stakeholders' wisdom.

Methods: This was a qualitative study in which the data were collected through reviewing documents and references, focused group discussions with experts, and interviewing the stakeholders. The data were analyzed and summed up as a conceptual framework. Then, the framework was developed as a health policy-making stakeholders' network protocol, which included the goal, structure, system process, procedures and standards, management style, and resources.

Results: The goal of establishing this network was to facilitate and accelerate the access of policy-makers to the stakeholders' opinions. Members of the network were divided into 2 groups of thematic experts and administrative managers, as real or legal persons. Health policy issues were categorized into 4 fields and defined in 18 subfields. The network was established through forming a national secretariat, under the supervision of the Minister of Health, with the presence of trained experts, and with an exclusive budget. The stakeholders participated in the network both actively and passively. The website and email were the first communication methods although there were also other policy dialogue means, which were publicly declared through the annual calendar. Stakeholders were motivated by being invited to meetings, keeping up their intellectual ownership, and encouraging them.

Conclusion: Strengthening the health system stewardship depends on using common sense and information in addition to vision formation and establishment of controlling mechanisms. The stakeholders' network could help establish the 2 last components sustainably. Annual evaluation of the network and its consolidation has also been suggested in this study.
\end{abstract}

Keywords: Health policy-making, Stakeholders' network, Iran, Developing countries

Copyright@ Iran University of Medical Sciences

Cite this article as: Damari B, Vosoogh Moghadam A, Rostamigooran N. Stakeholders' network in Iranian health policy-making: A model for participatory policy-making. Med J Islam Repub Iran. 2017 (19 Dec);31:106. https://doi.org/10.14196/mjiri.31.106

\section{Introduction}

The word "network" is widely used in different sciences and has various meanings. Human networks, whose members are real or legal persons, who interact with each other formally or informally, are under consideration of the humanistic sciences, including policy-making issues.

"Public policy" is an action that government decides to do or not to do, and "health policy" is a kind of public policy that deals with specific goals in the field of community health (1). One of the effective factors in legitimating the policies is participation of stakeholders in the process of policy-making (2). In other words, the policy stakeholders are a group of people whose views can facilitate proper development and policy implementation.

Thus, their points of view should not be neglected alt-

\footnotetext{
Corresponding author: Dr Narges Rostamigooran, rostamigooran@yahoo.com

1. NHIR, Tehran University of Medical Sciences, Tehran, Iran.

2. Secretariat of Supreme Council of Health and Food Security, MOH\&ME, Tehran, Iran.

3. Deputy of social Affair, MOH\&ME, Tehran, Iran
}

hough the importance of their opinions varies, so they should be identified and analyzed in each case $(3,4)$.

Generally, factors of experience, knowledge, opinion, and financial interests lead to formal and informal interactions of stakeholders of a specific policy (5).

Networks are one of these interactions. Some people believe that networks provide a way through which pyramid shape relations are disregarded and flat shape systems are used instead. Thus, all people equally affect the networks (6). Therefore, networks can make a ground in which knowledge and information can be interchanged more easily (7). Knowledge and social outcome are generally 2 important achievements of developing networks. Knowledge outcome means transferring the information

$\uparrow$ What is "already known" in this topic:

Participation in public health policy-making process is not a slogan, but it is a fact and necessity.

$\rightarrow$ What this article adds:

This study suggests a model for participating 4 groups of stakeholders and can be implemented in health policy-making. 
among network members and exchanging tacit knowledge including basic values, hypotheses, and beliefs (8) that cannot be easily transferred to others (9). The process of knowledge interchange and tacit knowledge sharing helps the organizations to move differently from their competitors (10). The key point in this regard is the importance of social communications and strength of these relations in integrating, sharing, producing, and transferring tacit knowledge (11). Knowledge interchange can be done best when individuals are in contact together and rely on themselves. Meanwhile, increasing communication in the official networks causes an increase in social capital and a decrease in the costs of performing jobs. Strengthening the culture of teamwork and participation of the members in decision- making facilitates accepting and implementing the approved decisions and policies $(2,12)$.

Studies have shown that the policy- making system of the Islamic Republic of Iran has several experiences on developing official networks of experts such as "the Experts Network of the Islamic Parliament Research Center" and "the Health Think Tank" of the Jihad - Daneshgahi of Shahid Beheshti University of Medical Sciences and Health Services $(13,14)$.

Those organizations that had a basic network structure were welcomed by the experts, elites, and policymakers, but could not continue their activities.

Using the stakeholders' comments was a necessity and main principle to scale up the health policy process at the Ministry of Health and Medical Education (MOHME) $(15,16)$.

The Supreme Council of Health and Food Security is a multispectral council, which is responsible for developing and implementing health policy by intersectoral collaboration (Fig. 1).

Proper functioning of this council involves using the common sense of their stakeholders. Managing this large

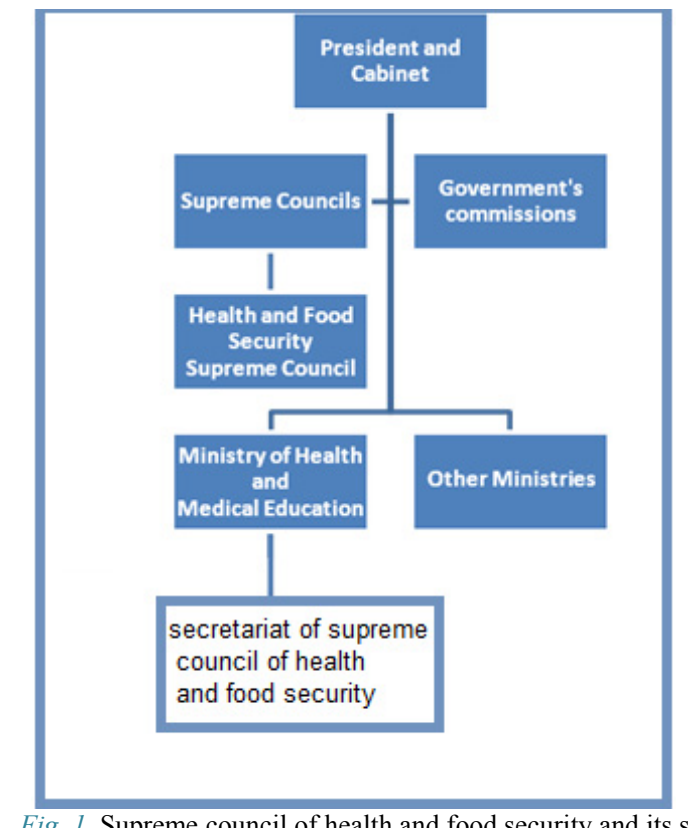

Fig. 1. Supreme council of health and food security and its secretariat number of stakeholders in the field of health and other sectors is difficult, so in this study we aimed at identifying the stakeholders' network of health policy-making and presenting it as a protocol.

\section{Methods}

This was a qualitative study in which 3 methods of reviewing documents and references, performing focused group discussions with the experts, and interviewing the stakeholders were used for data collection to design a network. After analyzing the data, information was summed up as a conceptual framework and then a protocol named 'the Stakeholders' Network of Health PolicyMaking" was developed, with sections including goal, structure, system process, procedures and standards, method of management, and resources.

\section{The first step: Reviewing documents and references}

This step included review of the published experiences, analysis of the previous interventions, and review of the supreme policy and legal documents.

a) At the first phase of the study, a specific search was done using the following keywords: "health policy", "stakeholder", "network", and "interest group" in valid websites such as World Health Organization (WHO), Google Scholar, PubMed, Iranmedex (Now it is substituted with Barekat Knowledge Network System(http://health.barakatkns.com/)), etc. The goal of the search was to find answers to the following questions:

1. What are the definition, principles of formation, and characteristics of a social network, and method of its management?

2. What experiences are there for the stakeholders' networks (at least in the field of policy-making) at international level?

3. What is the stakeholders' classification in the health system?

b) At the second phase, the previous interventions of developing the stakeholders' networks in Iran were searched. In this regard, 2 cases were found in the websites and library references: "the Expert Network of the Islamic Parliament Research Center" and "Health Think Tank".

c) The supreme documents including Iran's Constitution, the notified general policies by the supreme leader, and the act of the fifth 5-Year Development Plan were reviewed to find the supporting statements and principles in developing and approving this network.

All the above- mentioned data were presented to the technical steering committee, as the report of "reviewing the literature".

\section{The second step: Focused group discussion}

Six persons were selected as the members of the technical steering committee according to 3 following criteria: (1) working experience in the field of national policymaking, (2) having relevant specialty, and (3) authoring relevant books or articles. The output to the first step was delivered to them, and then, the components of the network were developed.

Five focused group discussions sessions were held to 
answer the following questions:

1. What is the definition of the stakeholder's network of health policy-making (subset of the health sector policy council) and its objectives?

2. What are the characteristics of this network and the criteria of including and excluding individuals and organizations?

3. What are the main process and participation procedures of the stakeholders?

4. What is the communicational structure of forming the units of the network?

5. How does the network be coordinated and managed?

6. How can the needed resources of the network's members be provided?

All the conversations were recorded and downloaded with the permission of those attended in the sessions. In each session, the results of the previous sessions were set forth. In case of any comments, there was the opportunity for presenting it. Finally, all the negotiations were summed up and the draft of the protocol was prepared from the stakeholders' network of health policy-making. The sessions were managed by a skilled person in managing focused group discussions.

The third step: Asking written comments from the stakeholders

The stakeholders were included 4 groups (managers, service providers, researchers, and representatives of people). Deputies of the Ministry of Health as well as the chancellors of universities of medical sciences and health services were selected as senior managers. Representatives of the service providers were 170 scientific societies of medical sciences. They were coordinated through the Secretariat of the Commission of Medical Scientific Societies. Peoples' representatives were the members of the health commission of Islamic Parliament.

The drafted protocol of policy-making stakeholders' network was distributed to the defined stakeholders by official corresponding of the Secretary of Health Sector Policy Council including the following 4 open questions:

1. Do you consider the protocol as necessary?

2. What are the strengths of the protocol?

3 . What are the weaknesses of the protocol?
4. What are your suggested obligations for perfect implementation of the protocol?

The answers were collected and applied in the protocol. Then, the final version of the protocol was submitted to the HPS to be approved.

\section{Results}

1. According to the results of literature review and steering committee' opinions, some principles for network formation were achieved as follow:

2. A protocol of network must include goals and visions, the route of information transition, ethical obligation for users, incentives for collaborative activity, inclusion and exclusion criteria, and some ways for detecting active members.

3 . The subjects need to be classified in thematic groups.

4. One of the main goals of network formation is facilitating knowledge translation and utilization; especially in policy- making process .This is highly important in designing the network.

5. Cost- effectiveness and efficiency must be considered in designing the network.

6. It is necessary that a secretariat and a trained officer be appointed for the network, but it must be avoided to establish complexities and expensive structure.

7. Network managers must provide feedback to all members periodically.

8. Financial resources and the cost of establishment and maintaining the network must be considered.

9. Both individuals and organizations should be able to register.

10. Two main groups in these networks are academic persons and managers.

11. The word "elite" should be avoided because it has different meanings and is contradictory.

12. The large number of specialist and academic persons, retired experts, and international consultants are some of the strengths that should be recognized.

Response rates of the stakeholders groups are presented in Table 1.

More than $77 \%$ of the correspondents believed that such a network is necessary for developing health policies. They named the advantages and disadvantages of the

Table 1. The response rate of the 4 groups of Stakeholders

\begin{tabular}{lc}
\hline Group & Total corresponding \\
\hline 1. Managers: Deputies of the minister of health and chancellors of medical universities & 70 \\
2. Service providers: Scientific societies & 110 \\
3. People: members of parliament's commission of health & 20 \\
4. Researchers: Three policy-making research centers & 80 \\
\hline
\end{tabular}

Table 2. Advantages and disadvantages of the stakeholders' network of health policy-making

\begin{tabular}{ll}
\hline \multicolumn{1}{c}{ Advantage } & \multicolumn{1}{c}{ Disadvantage } \\
\hline $\begin{array}{l}\text { Increases ownership feeling of the stakeholders } \\
\text { Issued health policies will be more stable }\end{array}$ & $\begin{array}{l}\text { Increases bureaucracy and puts the policy-makers under social pressure and time limitation. } \\
\text { People do not have any motivation to get involved in such processes, and so the protocol } \\
\text { can hardly be implemented. } \\
\text { No guarantee for using the stakeholders' comments }\end{array}$ \\
$\begin{array}{l}\text { Evaluation of the policy will be easier } \\
\begin{array}{l}\text { Accuracy and precision of the issued polices increase } \\
\text { Social capital of the experts and stakeholders will in- } \\
\text { crease }\end{array}\end{array}$ & $\begin{array}{l}\text { Unquantifiable viewpoints } \\
\text { Inequality of the participated stakeholders in agreement or opposition }\end{array}$ \\
$\begin{array}{l}\text { Better documentation } \\
\text { Culture of social participation and mutual answering } \\
\text { atmosphere is strengthened }\end{array}$ & Conflict of interests in gathering comments \\
\hline
\end{tabular}


stakeholders' network of health policy-making (Table 2).

Analysis of pros and cons suggests requirements for perfect implementation of the protocol of the stakeholders' network of health policy-making, which are as follow:

- Policymakers should issue the protocol and the senior managers of MOHME should be committed to its implementation.

- Urgent and shortcut policy formulation routes should be developed, so that issuing policies wouldn't be a long process.

- Stakeholders' motivation system should be established perfectly.

- Annual programs of stakeholders' education and evaluation should be done.

- There should be other participation methods such as interview for those stakeholders who cannot communicate through email.

- There should be strong and trained human resources for establishing such systems.

According to the 3 steps mentioned in the methodology, the stakeholders' network of health policy-making has been developed in 6 parts of goals, members, structure, management, communication methods, and motivation. The stakeholders' opinions (Table 1) were applied, and the parts are as follow:

\section{Goals of the network}

It is expected that policymaking process can be facilitated, and knowledge and experiences of the consultants be used better by:

- Facilitating the access to the evidence-based activities
- Facilitating geographical and timely access to the experts

- Receiving new issues and topics

- Informing about the health system policies and news

\section{Members of the network}

Members of the network are divided into thematic experts and administrative managers (Table 3 ).

To facilitate the utilization of knowledge and experience of network's members, a specialized classification was made for health fields. Thematic experts were classified into 18 fields, which can be revised (Table 4).

The specialists of each field can be classified again and make some subnetworks, which are managed by related managers. Having a specialty as well as relevant scientific publication in each subfield is necessary; this should be diagnosed by the network's manager.

To enter the network, all stakeholders should study the charter of cooperating in the stakeholders' network, sign it, and send it to the network's manager, so that their membership is finalized. The charter includes a form of user's information, Curriculum Vita, ethical principles paper, and the protocol. New members can both register through the website and be introduced by the previous members. The form can be sent to the nonmembers of the network too, so that the experienced people's information can be collected through snowball method.

\section{Structure and management of the network}

Headquarter of the network's management and place of supervising the protocol of the stakeholders' network of

Table 3. Categorizing the members of health consultants network

\begin{tabular}{|c|c|c|}
\hline Consultants & Individuals & Organizations/Councils/Networks \\
\hline Administrative & $\begin{array}{l}\text { Headquarter managers of MOHME; headquarter } \\
\text { managers of the related ministries; directors, } \\
\text { deputies, and managers of the related organiza- } \\
\text { tions }\end{array}$ & $\begin{array}{l}\text { Consultative and decision-making councils of the headquarter; aca- } \\
\text { demic councils; trustees boards of medical universities; specialized } \\
\text { workgroups of health and food security of the provinces ; health } \\
\text { policy-making council; managers council of the undersecretaries; } \\
\text { national councils of the deputies of medical universities; chancellors } \\
\text { council; parliament's health commission }\end{array}$ \\
\hline $\begin{array}{l}\text { Scientific } \\
\text { thematic experts }\end{array}$ & $\begin{array}{l}\text { Faculty members; headquarter and ground ex- } \\
\text { perts; non-faculty researchers; PhD students; } \\
\text { medical sciences specialists; experts of the } \\
\text { international organizations; representative offic- } \\
\text { es of international organizations in Iran. }\end{array}$ & $\begin{array}{l}\text { Public and private sectors research centers; parliament's research } \\
\text { center; NGOs and scientific associations; Iranian academy of medical } \\
\text { Sciences. } \\
\text { High council of provincial (as broker role of people participation) }\end{array}$ \\
\hline \multicolumn{3}{|c|}{ Table 4. Issue fields in the health consultant's network } \\
\hline Fields & & Subfields \\
\hline Stewardship & \multicolumn{2}{|c|}{$\begin{array}{l}\text { (1) Strategic planning and policy-making system; (2) Community participation; (3) Intersectoral cooperation; (4) Social } \\
\text { determinants of health; (5) Health rules and regulations; (6) responsiveness }\end{array}$} \\
\hline Resource generation & \multicolumn{2}{|c|}{$\begin{array}{l}\text { (7) Medical education; (8) Research management; (9) Health information management; (10). Medical equipment; (11) } \\
\text { Food and drug }\end{array}$} \\
\hline Financing & \multicolumn{2}{|c|}{ (12) Budget; (13) Payment system, insurances, and financial equity } \\
\hline Service provision & \multicolumn{2}{|c|}{$\begin{array}{l}\text { (14) First level services and health networks; (15) Second level services; (16) Third level services; (17) Prevention and } \\
\text { population health improvement; (18) surveillance systems }\end{array}$} \\
\hline
\end{tabular}


health policy-making is the Secretariat of the Supreme Council of Health and Food Security.

Establishing primary structure, financing, monitoring, and evaluating the network of health consultants is done in this secretariat. The network's manager is a person with at least an MPH degree, who is appointed by the Head of the Secretariat of the Supreme Council of Health and Food Security. The costs of the network are provided by the exclusive budget from MOHME. Specialists, retired persons, international consultants with previous experience in Iran, and talented students can help in the continuity of this network through activating it.

\section{Communication methods}

Participation methods in the opinion poll of the network are active and passive. In the active method, the selected people are questioned directly about their opinions. However, in the passive method, members of the network are informed about the poll and can participate in itvoluntarily. The first and most important communication method is through the website and email. Other methods in this regard are as follow:

1. Specialized meetings in the field of health policymaking

2. SMS for important and prioritized news

3. Annual meeting of thematic experts with specific agenda

4. Annual face to face communication of the networks' members at universities of medical sciences

5. Specialized meetings in the field of health policymaking aby video conference

\section{Motivation}

Choices for meeting intellectual rights of people are as follow:

1. Financial rewards should be considered for those who cooperate in developing policy papers

2. A privilege for promotion of faculty members

3. Noting names of correspondents in the policy paper as cooperating members (meeting intellectual rights of those attended in the opinion poll)

4. Declaring the list of active participators annually, and issuing appreciation letter for them from the health policymaking department

5. Providing probability of using network's facilities for the members, after approval of the Secretariat of the Supreme Council of Health and Food Security

6. Electronic access to the center of strategic documents of MOHME

7. Regular feedback from network's designers to all network members through email

8. Sending the defined scientific references by the Secretariat of Health Policy-making freely

\section{Discussion}

In this study, which was done using qualitative tools and techniques, the validity of the results was confirmed by sending the results for the steering committee that attended in discussions and interviewed persons. According to the results of this study, the goal of establishing the network was to facilitate the access of policy-makers to the opinions of the stakeholders. Members of the network were divided into 2 groups of case specialists and administrative managers, as real or legal persons. Four fields and 18 subfields were determined for the policies.

The network would be established through development of a national secretariat, cooperation of the trained experts, and under the supervision of the Minister of Health, with an exclusive budget.

The stakeholders could participate in the network actively or passively. The first communication method is the website and email, but other possible methods are publicly declared according to the annual calendar. Participators are motivated through meeting their intellectual rights based on the due regulation of the protocol. Using the present opportunities and facilities is one of the strengths of this protocol, so the network is developed under the Supreme Council of Health and Food Security at MOHME, which has a defined process for supporting policy- making and the network would complete this process.

The other strength of the protocol is using a large number of stakeholders in the opinion poll that helps its acceptability.

Network concept was developed when the advantages of teamwork were determined in communities. Teamwork in each field results in better achievements than individual working and can also prevent resources wasting. In such condition, the knowledge level of the community increases. Also, sharing the experiences causes the possibility of difficulties. In general, coalitions or networks have more strength for advocacy in governmental bodies (17). These facts are in conformity with the findings of this study.

According to Peri et al., although the concept of network is hardly defined and understood and there are few researches on the effectiveness and evaluation of the networks, development of organizational and professional networks has a great effect on the quality of social and health care in the future. This involves an efficient management and effective cooperation of the network. Based on the systematic review of Peri et al., characteristics of an effective management in a network are as follow:

1. Compiling a distinct mission for the network and free of conflict regulation for involving its members

2. Emphasizing the users instead of the structure in designing the network

3. Preventing the development of vast networks due to its increased costs and neglecting the goals

4. Maintaining the groups through providing the needed budgets

5. Entrusting the responsibility of networks' coordination affairs to the institutions with respectable members

6 . Coordinator of the network should be provided for financially

7. Managers need time to learn the skills of managing networks

8. Coordinators should be controlled and should also be the reference of knowledge and information (18)

According to these items, it seems that establishing the 
management of the stakeholders' network of policymaking at the MOHME, which has enough facilities to coordinate the members and financially support the network, is a true resulting and helps its establishment at least at the beginning of the job. Nonetheless, apart from the structure, the working process of the network is also important. The following question should be answered: What are the expectations of policy-makers from the stakeholders who are supposed to cooperate with the network?

In general, the following roles are defined for the stakeholders in the process of policy-making:

1. Participating in the policy-making process with presenting views and comments

2. Presenting experiences and tacit knowledge in the specialized fields

3. Becoming familiar with policy-making process and method of developing and implementing policies

4. Directing the attention of the policy-makers to the values and beliefs and other grounding problems, which can affect the implementation of a policy

5. Presenting new issues as well as data and information to the decision-makers

6. Representativeness of people and communities that cannot directly intervene in the policy-making process

7. Advocacy of other groups for implementing a new policy

8. Monitoring the function of the policy-makers $(3,5)$

A newly established network cannot do all the abovementioned roles. Therefore, according to the principals of an evidence- based policy-making (3), receiving the comments and suggestions are the first job of the network.

The important point in interacting with individuals for cooperating under a network is to consider their motivations for connecting to the network and continuing their cooperation.

Mullin et al. (19) found that people's reason for joining a network are as follow:

1. Responding to the organizational needs

2. Coordinating the goals of networks with their organizations

3. Improving professional skills and increasing mental capital through sharing thoughts and ideas (19)

Bartonk et al. pointed to the importance of accepting individual and group differences in continuation of a network's activity. People come together from different groups to develop a network, but if the dynamism of intergroup behavior is not met, the cooperation cannot $b$ result in a proper conclusion (20). Therefore, some rewards should be considered in the stakeholders' network of health policy-making.

Motivating people to participate in the process of policy-making is also important from the aspect of conflict of interests (3). Thus, before sending the documents or holding meetings, analysis of the stakeholders should be done on the considered policies, so that their opinions can be explained and studied. This doesn't mean denying the opposite ideas, but it should be considered that presence of individual or group interests can affect the acceptance or rejection of policies, and this should not be neglected by the policy-makers.
To propose the protocol of the network, we used an action research method. Although this was not usual in the administrative process using research method, we think it helps increase the validity of the defined process.

One of the restrictions of this study was lack of using the opinions of people who are out of health sector; and the other limitation was that we did not pilot the protocol. Thus, we recommend conducting more studies on the implementation and evaluation of such networks.

\section{Conclusion}

In general, the stakeholders' network of health policymaking has 3 advantages as follow:

1. It makes a backing to issue health supporting policies

2. It Facilitates the exchange of knowledge and transfer of experiences

3 . It increases the social capital of the members and decreases the costs of developing and implementing the policies

Strengthening the stewardship in Iranian health system depends on using common sense and information as well as creating vision and establishing controlling methods. The stakeholders' network helps in permanent establishment of these 2 items. Annual evaluation of the network and its strengthening is highly suggested.

\section{Conflict of Interests}

The authors declare that they have no competing interests.

\section{References}

1. Dye TR. Understanding Public Policy. 13th ed: Pearson; 2010.

2. RugerJP. Shared Health Governance. Am J Bioeth. 2011 Jul;11(7): $32-45$.

3. Lavis JN, Boyko JA, Oxman AD, Lewin S, Fretheim A. SUPPORT Tools for evidence-informed health Policy making (STP)14 Organising and using policy dialogues to support evidence-informed policymaking. Health Res Policy Syst. 2009; 7(Suppl 1): S14.

4. Keshtkar AA, Djalalinia Sh, Khashayar P, Peykari N, Mohammdi Z, Larijani B. Iranian Health Research Networks and Vision of Iran by 2025: A Case of Virtual Health Network in EMRI. Iranian J Publ Health, 2013; 42(Supple1):78-83.

5. Oxman AD, Lewin S, Lavis JN, Fretheim A. SUPPORT Tools for evidence-informed health Policymaking (STP) 15: Engaging the public in evidence-informed policymaking. Health Res Policy Syst. 2009;7(Suppl 1):S15.

6. Powel WW, White DR, Koput KW, Owen-smith J, Bresnahan T, David P, et al. Network daynamics and field evolution: The growth of interorganizational collaboration in the life sciences. AJS. 2005; 110(4):1132-1205

7. Yazdizadeh B, Majdzadeh R, Alami A, Amrolalaei S. How can we establish more successful knowledge networks in developing countries? Lessons learnt from knowledge networks in Iran. Health Res Policy Syst. 2014;12:63.

8. Nonaka I, Toyama R, Konno N. SECI, Ba and Leadership: a Unified Model of Dynamic Knowledge Creation. Long Range Planning, 2000; 33(1):5-34.

9. Sheffield J. Inquiry in health knowledge management. JKM. 2008; 12(4):160-172.

10. Nonaka I,von Krogh G. Tacit Knowledge and Knowledge Conversion: Controversy and Advancement in Organizational Knowledge Creation Theory. Organiz Sci. 2009;20(3): 635-652.

11. Nie k, Lin Sh, Ma T, Nakamori Y. Connecting Informal Networks To Management Of Tacit Knowledge. J Syst Sci Syst Eng. 2010;19(2):237-253.

12. Eriksson M. Social capital and health - implications for health promotion. Global Health Action. 2011;4:10. 
13. Islamic Parliament Research Center. Users webpage. Available from: http://rc.majlis.ir/fa/member/register. [Accessed date: 10 May 2015].

14. Damri B, Vosoogh-Moghaddam A. Designing Health Think Tank. Jihad-Daneshgahi of Shahid Beheshti University of Medical Scinces and Health Services. Tehran; 2008.

15. Vosoogh Moghaddam A, Damari B, Alikhani S, Salarianzedeh MH, Rostamigooran N, Delavari A, et al. Health in the 5th 5-years Development Plan of Iran: Main Challenges, General Policies and Strategies. Iran J Public Health. 2013;42(Supple1):42-49.

16. Damari B, Vosoogh-Moghaddam A, Monazzam K, Salarianzadeh H Where and How to Make Wise Policies for Health? A Qualitative Study on the Characteristics of Health Policy System in the Islamic Republic of Iran. Hakim. 2011;13(4):210-218.

17. Gainforth HL, Latimer-Cheung AE, Moore S, Athanasopoulos P, Martin Ginis KA. Using Network Analysis to Understand Knowledge Mobilization in a Community-based Organization. Int J Behav Med. 2015;22(3):292-300.

18. Goodwin N, Perri G, Peck E, Freeman T, Posaner R. Managing across diverse networks of care: lessons from other sectors Health Services Research Unit,London: London School of Hygiene and Tropical Medicine; 2004.

19. Mullen CA, Kochan F. Creating a collaborative leadership network: an organic viewof change. Int J Leadership In Education. 2000;3(3): 183-200.

20. Bartunek J, Trullen J, Bonet E, Sauquet A. Sharing and expanding academic and practitioner knowledge in health care. J Health Serv Res Policy. 2003;8 Suppl 2:62-8. 